\title{
2013 was a horrible year for nursing—nurses are "burnt out," says chief
}

\author{
Nurses have been scapegoats in scandals over poor quality care when the main problem is \\ understaffing, Peter Carter, head of the Royal College of Nursing, tells Chris Mahony
}

Chris Mahony freelance journalist

London, UK

The reaction to the Mid Staffs scandal focused too much on nurse training and not enough on the fact that experienced nurses and their NHS colleagues are "burnt out" by understaffing, according to Peter Carter, chief executive and general secretary of the Royal College of Nursing. In a wide ranging interview, Carter said that until staffing levels are increased, it will not be possible to guarantee quality nursing care.

"The Francis report [into failings at Mid Staffs trust] showed that on some occasions there were two nurses on 34 bedded wards for elderly people," said Carter. "The two nurses could have been Florence Nightingale, but with that ratio you simply cannot provide quality care."

The college keeps pointing out that there is a "growing body of evidence ... that the only way to ensure patient safety is to have adequate staff with the right skills," and this was a key recommendation of the Francis report.

Yet the government has so far failed to act on those recommendations, Carter says.

"My worry is this: we have a plethora of reports and inquiries and the recommendations that tend to get implemented are the ones ... that don't have resource implications while [those with] resource implications tend to disappear into the long grass over time."

One trust, the Basildon and Thurrock University Hospitals NHS Foundation Trust, announced it would recruit 200 more nurses within hours of the report by NHS England's medical director Bruce Keogh in May highlighting 14 trusts thought to be at risk of similar failings to Mid Staffs.

"You could not get a more tangible example of a hospital that has finally been brought to understand that if you cut frontline staff the net effect is going to be poor standards," says Carter, who was chief executive of an NHS trust for 12 years.

But at government level—and in the media-there has been little attention to the question of staffing and too much "vague talk" about the need for a "change of culture," which does not deal with the concrete concerns.

"At some point downstream somebody is going to have to say, 'you can talk about values and cultural change . . . but unless you have got infantry on the ground it is never going to work.' We are quite clear that ultimately a government will have to 'fess up' to this."

\section{Training is not the problem}

Public discussion has focused on how university trained nurses lack compassion or are "too posh to wash." Carter says that student nurses spend about half of their three year preregistration training time, 2300 hours, in clinical practice, so it is misinformed to suggest that this generation of nurses don't expect to provide basic care.

"Cleaning up doubly incontinent patients and emptying bedpans comes with the territory, and if anyone thinks they can somehow be a nurse without doing those things then they have been seriously misdirected, but I honestly think it has been really overstated."

Reports on the profession's failings, media attacks on nurses for lacking compassion and a salary freeze put nursing through its own annus horribilis in 2013, says Carter.

Health secretary Jeremy Hunt's call for an extra year of practical experience for student nurses missed the point, Carter says.

"The majority of nurses appearing before the Nursing and Midwifery Council ... qualified 25, 30, or 35 years ago.

"These are people who are burnt out and have lost their edge." The college's long term goal is to have legally enforceable minimum staffing levels based on the Australian model, which has been very successful.

Meanwhile nurses feel unfairly targeted.

"Of course nurses think, 'My God we slog our guts out.' Patient satisfaction with nursing care in most hospitals is 
overwhelmingly high, but they are still getting criticism, which I think is ill directed," says Carter.

He asks why trust managers who continued to push for cuts in staffing levels have not been equally criticised.

"If a nurse has behaved in a way they ought not to and there are no mitigating circumstances, they have to be held responsible. Equally, when nurses and indeed our colleagues in other disciplines are put in situations where it is simply not viable to carry out good quality care because there is insufficient staff, where is the responsibility on the senior people in the trust? The emphasis is often on frontline junior people, and that doesn't stack up to be very fair in my book."

\section{Distractions}

Hunt's proposal to require nursing students to complete a year's work as a healthcare assistant before beginning training could be seen as a major distraction from the more important recommendations of the Francis report, Carter says.

"That was like recommendation 291 from Jeremy Hunt [the report contained 290]. It was a deflection from the Francis report, either conscious or otherwise.

"We think the secretary of state was well intentioned when he came up with this, but we think it is the wrong answer to the wrong question ... I wish he'd spoken with people because you do not need to have done a year as a healthcare assistant to demonstrate that you are appropriate to be a nurse. What you have to demonstrate at interview and in the selection process is that you have empathy and people skills as well as an understanding of what you are doing."

In an effort to work constructively with the government, the college is working with Health Education England on pilots for Hunt's proposal.

Carter is disappointed too that other recommendations in the Francis report have not so far been accepted. Francis called for a return to the days when ward sisters were supernumerary, pointing to the 2006 inquiry into poor care and crammed wards at Maidstone and Tunbridge Wells NHS Trust.

"One of the things people talk about when they talk about the 'good old days' - and they weren't all that great - is that the ward sister had the stature and authority to run the ward. I can guarantee you that in those days there is no way a ward sister would have put up with managers coming down and saying they were putting eight more beds in her ward. You talk about changing the culture: one of the cultural changes could have been respecting the role of ward sisters-give them the status and authority but also hear what they have to say.'

Competing interests: I have read and understood the BMJ policy on declaration of interests and have no relevant interests to declare.

Provenance and peer review: Commissioned; not externally peer reviewed.

Cite this as: $B M J$ 2014;348:g126

๑ BMJ Publishing Group Ltd 2014 


\section{Nurse education}

With dropout rates on some university nursing courses running at $25 \%$, Carter calls for a focus on the selection processes at some universities (nursing courses are heavily oversubscribed). He strongly agrees with Francis that students should spend three months delivering hands-on patient care as early as possible in their education.

An issue Carter thinks that Francis missed was the questionable quality and appropriateness of a small percentage of placements. He certainly does not believe that "compassion" can be taught-as much of the reporting of the Francis report seemed to imply.

And just as the current acute care hospital model has to adapt to the realities of a hospital population largely made up of older people with comorbidities, so preregistration nurse education should equip trainees with the relevant skills.

"These are often highly complex long term conditions, and there is a simplistic view of caring for older people that all you need is some TLC [tender loving care] and a bit of common sense. You need those attributes but you also need people properly trained in the care of older people," said Carter.

He also says that reporting of concerns about abuse or poor care should be encouraged as a formal part of nursing training so that nurses feel safer about raising concerns that their employers may not appreciate. Currently, he says, it is mostly students and volunteers who report problems. 